\title{
EBERT VERSUS SCHRETTINGER, DA LÓGICA CULTURAL (BIBLIOGRAFIA) À LÓGICA BIBLIOTECÁRIA (BIBLIOTECONOMIA)?
}

\author{
EBERT VERSUS SCHRETTINGER, DE LA LÓGICA \\ CULTURAL (BIBLIOGRAFÍA) A LA LÓGICA \\ BIBLIOTECARIA (BIBLIOTECOLOGÍA)?
}

Fiammetta Sabba ${ }^{2}$

\begin{abstract}
RESUMO
Introdução: Após a fundamental práxis bibliográfica de Gesner e após o fundamento cultural discutido por Naudé, que unificou exigências práticas e alicerces culturais, as evidências específicas e 0 amadurecimento teórico da Bibliografia e da Biblioteconomia passam a ser definidas e teorizadas em uma perspectiva de contraposição e uma dialética científica apaixonada, por Friedrich Adolf Ebert e por Martin Wilibald Schrettinger. Objetivo: Identificar e analisar as contribuições de Ebert e Schrettinger perante a consolidação da Bibliografia pura e do nascimento da Biblioteconomia moderna. Metodologia: Trata-se de uma pesquisa de fundo bibliográfico, realizada a partir da interpretação das fontes de Ebert e Schrettinger em combinação com revisão de literatura, por meio de abordagem histórica. Resultados: Ebert e Schrettinger, tendo criticado cada um os trabalhos do outro, desde sempre
\end{abstract}

\footnotetext{
${ }^{1}$ N.T.: Tradução do italiano para o português por Giulia Crippa (USP). Revisão técnica do texto e das imagens, revisão da tradução e notas da tradução por Andre Vieira de Freitas Araujo (UFRJ).

2 N.T.: Professora Associada no Departamento de Bens Culturais da Universidade de Bolonha (Campus de Ravenna), no Bacharelado em Ciências do Livro e do Documento. Possui doutorado em "Ciências Bibliográficas, Arquivísticas, Documentárias e para a Restauração e a Preservação dos Bens Bibliotecários e Arquivísticos" pela Universidade de Udine, com orientação de Alfredo Serrai e co-orientação de Attilio Mauro Caproni. Ministrou aulas e cursos de Bibliografia e Biblioteconomia nas Universidades e nos Institutos de Pesquisa de Perugia, Florença, Macerata, Parma, Roma. É diretora da Revista Internacional de Estudos Bibliográficos Bibliothecae.it (Universidade de Bolonha) e foi curadora do II Bibliotecario (Roma, Bulzoni) e responsável da redação de Bibliotheca (Milano, SylvestreBonnard). Faz parte do corpo editorial dos periódicos brasileiros "Perspectivas em Ciência da Informação" (UFMG) e "InCID: Revista de Ciência da Informação e da Documentação (USP)". Também é membro do Grupo de pesquisa Bibliotheca Disciplinata liderado por Giulia Crippa (USP). Email: fiammetta.sabba@unibo.it
} 
foram ilustrados em contraposição, mas seu embate foi o terreno sobre o qual passou a se definir o pensamento bibliográfico e biblioteconômico de ambos. Conclusões: Os elementos que aproximam as teorias de Ebert e Schrettinger, e que são fundamentais para a Biblioteconomia, são essencialmente dois: a figura do bibliotecário e o catálogo. O bibliotecário deve ser bem selecionado, além de ser apoiado tanto financeiramente como nas ações de atualização e de estudo. O catálogo, com efeito, é, porém, o elemento que junta os dois bibliotecários (Ebert e Schrettinger): sem o catálogo da coleção de livros constituída pelas coleções individuais não pode ser substanciado qualquer raciocínio nem bibliográfico nem biblioteconômico, seja a visão baseada naquela tradicionalmente erudita e literária, seja que se trate da nova e moderna configuração de tipo organizacional e gerencial.

Descritores: Bibliografia - Alemanha - Séc. XIX. Biblioteconomia - Alemanha - Séc. XIX. Bibliografia e Biblioteconomia - Fundamentos. Friedrich Adolf Ebert (1791-1834). Martin Wilibald Schrettinger (1772-1851).

\section{INTRODUÇÃO}

A Bibliografia e a Biblioteconomia são as disciplinas que hoje ainda nos oferecem as duas estruturas, diversas porém complementares, com as quais se organiza e se realiza a atividade de documentação libraria ${ }^{2}$ (ainda que, hoje, não somente libraria). Pode-se falar em 'documentação' quando entendemos o conjunto dos documentos, portanto a atividade de seu fornecimento, bem como o próprio efeito exercido sobre a comunidade pela coleção e pela gestão racional dos documentos, enquanto registro e disponibilização da memória escrita.

Em uma síntese que pode ser o pressuposto de nossa ilustração, a Bibliografia, na medida em que determina as estruturas de classificação conforme as árvores do conhecimento e do saber, aplica-se também à disposição dos livros nas estantes, aos quais é, sucessivamente, dada ulterior

\footnotetext{
2 N.T. : O termo libraria/librario, de acordo com Araújo [tradutora] (2014, p. 208), significa " 'relativo aos livros', 'de livros', 'próprio dos livros', 'que se relaciona com o livro'. [...] está também relacionado ao local onde o livro era produzido (taller librario) e às práticas e às técnicas que o materializam. Pode referir-se, ainda, ao local de guarda dos livros - a biblioteca". Cf. RUIZ GARCIA, Elisa. Tipologia do livro. Tradução de Diná Marques Pereira Araújo. Cadernos de História, Belo Horizonte, v. 15, n. 23, p. 208-228, out. 2014. ISSN 2237-8871. Disponível em: <http://periodicos.pucminas.br/index.php/cadernoshistoria/article/viewFile/P.22378871.2014v15n23p208/7221 >. Acesso em: 15 jun. 2018.
}

Inf. Inf., Londrina, v. 23, n. 2, p. $203-231$, maio/ago. 2018 http://www.uel.br/revistas/informacao/ 
evidência através dos índices por autores e por assunto (também nossos atuais catálogos, constituídos por authority files, vale lembrar, não passam de um conjunto de índices).

Durante o evento realizado na Universidade Federal do Espírito Santo (UFES) no dia 8 de dezembro de 2017 a estudiosa Marilda Gines Lopez de Lara $^{3}$ especificou como a bibliografia, "um termo plural, polissêmico utilizado para nomear um produto, uma atividade, um campo disciplinar", desenvolveuse adotando práticas distintas de classificação, conforme seus objetivos orientados à pesquisa, seja ela com finalidades pragmáticas ou com interesses relativos aos próprios livros.

Quando, por outro lado, uma coleção de livros é colocada à disposição dos leitores, a organização que, com essa finalidade, é preparada, passa a ser tarefa e ofício da Biblioteconomia, que cuida dos aspectos de gestão do conjunto dos livros/documentos (as coleções) e das atividades aplicadas (os serviços) à sua distribuição e fruição, bem como da promoção da leitura e da pesquisa através deles.

Depois da práxis bibliográfica fundamental de Conrad Gesner, e depois do fundamento cultural argumentado por Naudé, que unira, em seu Advis pour dresser une bibliothèque (1627), exigências bibliotecárias práticas e fundamentos bibliográfico-culturais, a evidência específica e o amadurecimento teórico das duas disciplinas, isso é Bibliografia e Biblioteconomia, passam a ser agora definidas, ainda que em uma perspectiva aparentemente contraposta e debatida, por Friedrich Adolf Ebert e por Martin Wilibald Schrettinger.

Ebert e Schrettinger, com efeito, tendo criticado cada um os trabalhos do outro, desde sempre foram ilustrados em contraposição, mas seu embate, na realidade, foi o terreno sobre o qual passou a se definir o pensamento bibliográfico e biblioteconômico de ambos; tratou-se, de fato, de uma discussão que, mesmo adquirindo traços de competição individual, e sendo assim influenciada por aspectos emocionais, pessoais e subjetivos, contribuiu a

\footnotetext{
${ }^{3}$ N.T. : Professora do Programa de Pós-Graduação em Ciência da Informação da Escola de Comunicações e Artes da Universidade de São Paulo. Bolsista de Produtividade em Pesquisa, CNPq.
} 
destacar algumas das questões fundamentais das duas novas disciplinas, a Bibliografia e a Biblioteconomia.

A metamorfose e a evolução científica de Schrettinger foram, de fato, por exemplo, de nível teorético e de importância prática não inferiores aqueles vividos por Ebert; por essa razão decidiu-se, aqui, inverter a perspectiva canônica que geralmente introduz as duas personagens em termos contrapostos, enquanto é considerada metodologicamente desviante com a finalidade de compreender os fundamentos de suas teorias, para assim fazer emergir os pontos não somente de choque de suas visões científicas mas, principalmente, os de encontro que, ao nosso ver, ao contrário do que é afirmado até hoje na literatura específica, são deveras muitos (SERRAI, 1990b, 1990c).

Dessa maneira, para devolver a cada um dos dois bibliotecários a efetiva responsabilidade perante a consolidação da Bibliografia pura e do nascimento da Biblioteconomia moderna, providenciaremos, agora a analisar, em um primeiro momento de forma separada, suas contribuições especificas.

\section{FRIEDRICH ADOLF EBERT (1791-1834) ${ }^{4}$}

Ebert (Fig. 1), filho de um pastor luterano, tivera formação teológica e, em seguida, filosófica e clássica, e já se tornara, com 15 anos, auxiliar bibliotecário na biblioteca cívica de Leipzig. Mais tarde foi nomeado secretário da biblioteca real de Dresden, mas de 1823 a 1825 mudou-se para Wolfenbüttel com a função de bibliotecário do duque de Brunswick, ${ }^{5}$ para depois voltar à Dresden e se tornar, finalmente, bibliotecário chefe daquela Biblioteca Real em 1828. Sobre sua atividade de bibliotecário em Dresden e Leipzig, Ebert deixou também um diário, publicado para a década de 18131822. Ebert se ocupara também de construir as bibliografias das edições de Francesco Petrarca e de Torquato Tasso ${ }^{6}$.

\footnotetext{
${ }^{4}$ Cf. Bürger (1910), Jochum (1991) e Nestler (1960).

${ }^{5}$ Sobre este período, cf. Heinemann (1894).

${ }^{6}$ Sobre sua vida e suas obras consulte-se, além da obra citada de Nestler (1960), Bürger (1910).
} 
Figura 1 - Friedrich Adolf Ebert (1791-1834)

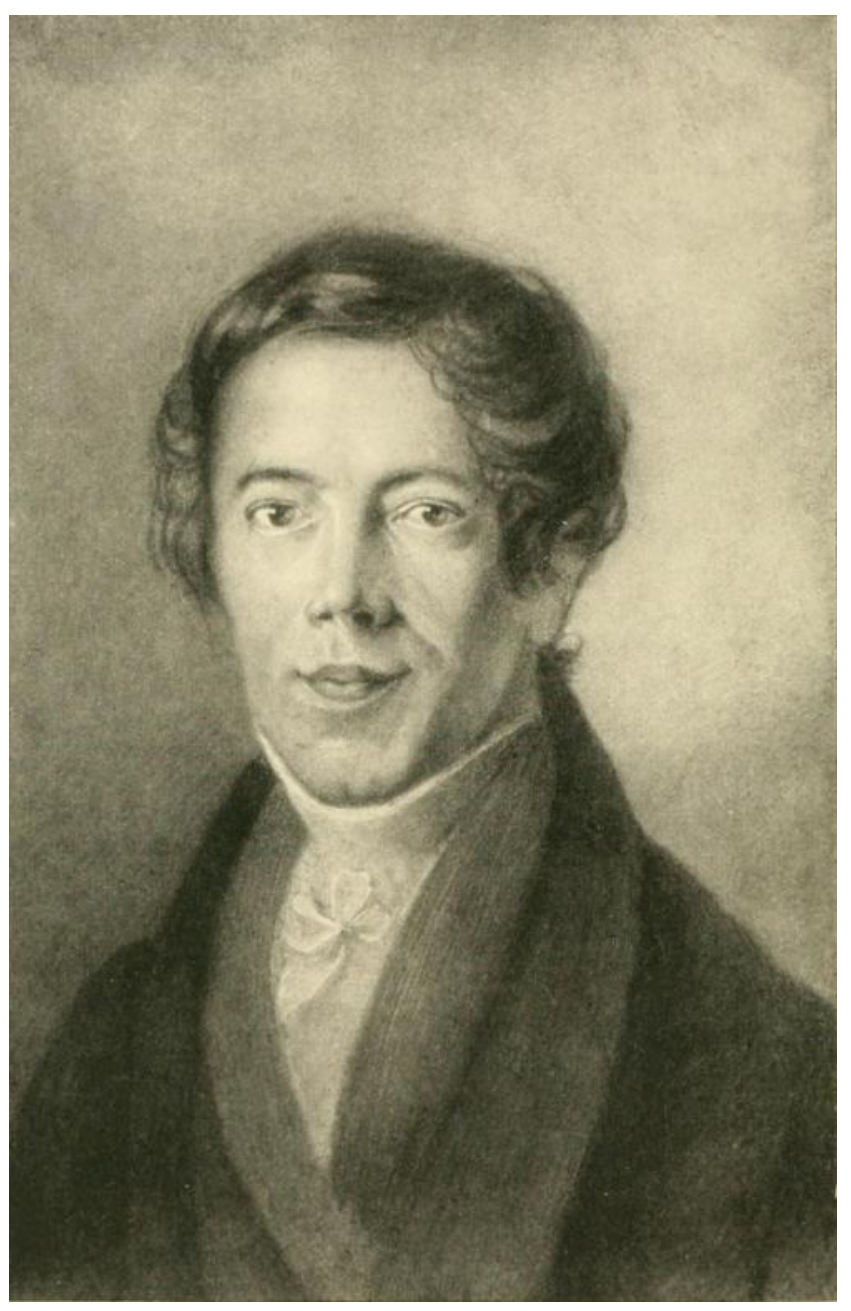

Fonte:

$<$ https://en.wikipedia.org/wiki/Friedrich_Adolf_Ebert\#/media/File:Friedrich_Adolf_Ebert, _Lichtdruck.png>

A obra pela qual Ebert é mais lembrado, a primeira de sua tipologia produzida em área alemã, é o Allgemeines bibliographisches Lexikon (Fig. 2), cujo primeiro volume foi impresso em 1821 e o segundo bem nove anos depois, em 1830. Além desse trabalho fundamental, as principais obras de Ebert, que coincidem exatamente com aquelas lembradas em relação às disciplinas de Bibliografia e de Biblioteconomia, foram:

- Die Bildung des Bibliothekars (1820) (tratado sobre formação de bibliotecários);

- Geschichte und Beschreibung der königlichen Bibliothek in Dresden (1822) (obra sobre a história e a descrição da biblioteca real de Dresden); 
- Zur Handschriftenkunde (1825-1827);

- Culturperioden des obersächsischen Mittelalters (1825).

Figura 2 - Allgemeines bibliographisches Lexikon (1821)

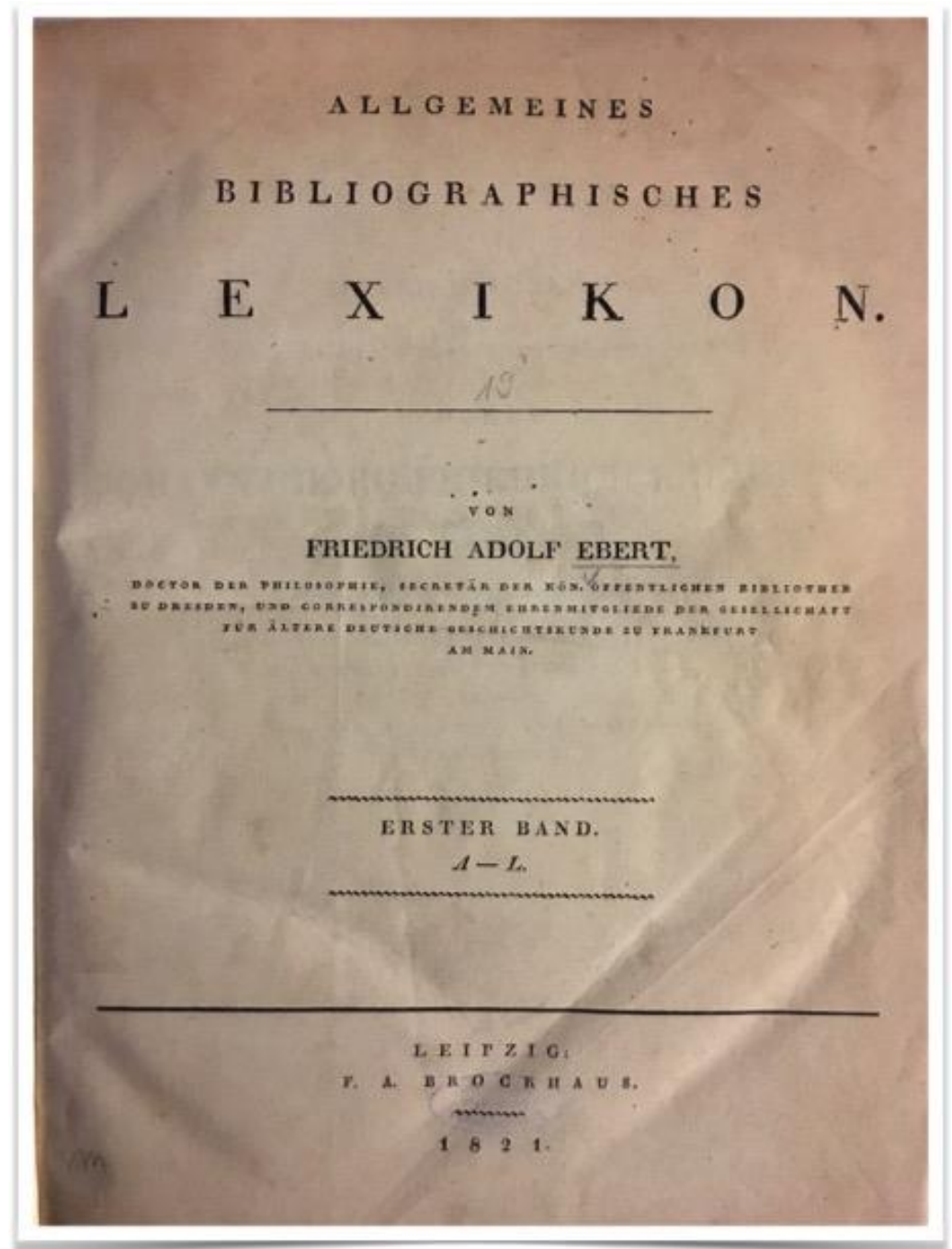

Fonte: Arquivo Alfredo Serrai.

Ebert expõe seu "bibliopensamento", antes que na Vorrede de Allgemeines bibliographisches Lexikon (Fig. 3), em algumas resenhas na nova revista Hermes. Juntando ambas as fontes, é possível reconstruir um panorama crítico das exposições e das práxis bibliográficas que circulavam à época. 
Figura 3 - Vorrede de Allgemeines bibliographisches Lexikon (1821)

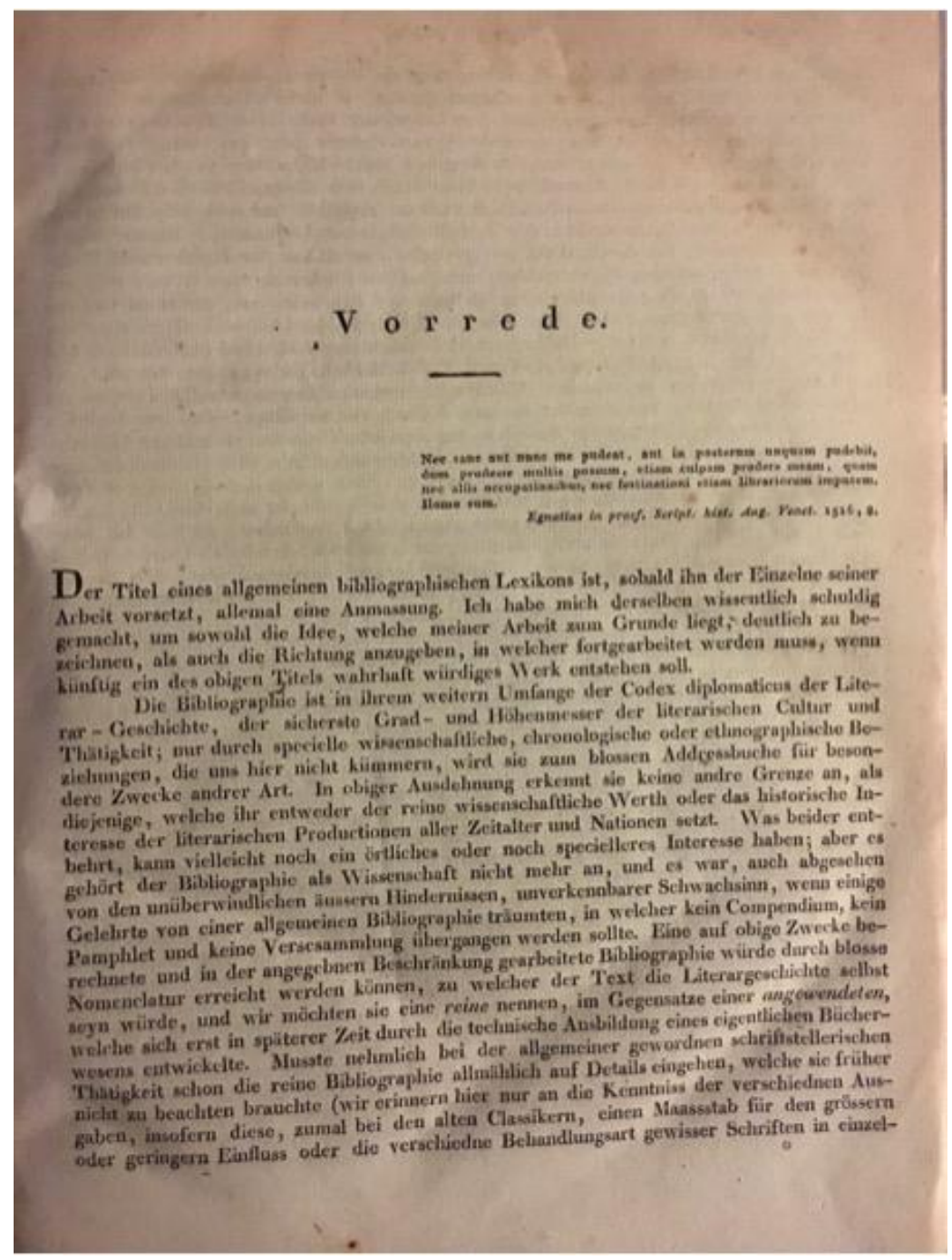

Fonte: Arquivo Alfredo Serrai.

Criticando a condição bibliófilo-antiquaria, bastante distante da verdadeira Bibliografia, Ebert assinala, entre os tratados que a ela pertencem, aquelas de Thomas Frognall Dibdin e dos franceses Renouard (em particular, o Catalogue de la Bibliotheque d'un amateur) e Brunet, de quem denuncia os erros, a falta de cuidado e de exatidão, a ponto de minar sua geralmente altíssima opinião dos trabalhos bibliográficos franceses.

Por outro lado, sua apreciação se orienta para os trabalhos catalográficos dos italianos Angelo Maria Bandini, Gian Vincenzo Pinelli, e Giambattista Audiffredi, mas, em particular, para aquele do alemão Johann 
Michael Francke, bibliotecário do conde Heinrich von Bünau, autor do incompleto Catalogus bibliothecae Bunavianae. Ainda, expressa apreciação para os repertórios biobibliográficos de outros eruditos italianos, tais quais Giovanni Maria Mazzuchelli, Gaetano Fantuzzi e Girolamo Tiraboschi.

Ebert, em relação às empreitadas bibliográficas universais, elogia a parte nominal alfabética da Bibliotheca Universalisde Gesner (1545), mas não as Pandectae (1548-1549), nem os vários volumes da Bibliotheca realis (Juridica 1679, Medica 1679, Philosophica 1682, Theologica 1685) de Martin Lipen, considerando que sua impostação fosse já totalmente ultrapassada pelo desenvolvimento das ciências. Com efeito, enquanto a parte alfabética permanecia válida sempre na busca de obra e de edições, a parte sistemática classificada resultava já totalmente anacrônica em documentar um âmbito ou um assunto de interesse científico.

Por outro lado, em relação à literatura bibliográfica doméstica (isso é, alemã), ele aprecia os trabalhos de Conrad von Uffenbach, do conde Heinrich von Brühl, e do conde Heinrich von Bünau, que manifestaram uma clara atenção voltada às coleções de livros; ainda, pelo auxílio dado ao conhecimento, tanto disciplinar como da literatura, expressa apreciação pelo trabalho de Johann Samuel Ersch (que deu início à bibliografia moderna), do bibliotecário filólogo Jeremiah David Reuss, de Georg Wolfgang Franz Panzer, que desenvolvera particularmente os Annales typographici, e de Johann Georg Meusel, alemão, mas que se engajara prevalentemente na bibliografia francesa.

Já por esta posição crítica compreende-se como, para Ebert, as premissas para um autêntico tratado de bibliografia eram de distinguir entre as intenções bibliográficas culturais e os interesses típicos do colecionismo, tanto inglês - que como declarado pelo próprio Dibdin, correspondia a uma espécie de 'bibliomania' - como daquele comercial holandês e, ainda, daquele bibliófilo francês, que no final das contas, porém, Ebert salva.

Além de uma 'Bibliografia pura', explica Ebert na Vorrede, de fato estava se produzindo o caminho para uma 'Bibliografia aplicada' que, em tempos recentes, através da formação técnica, desenvolvera-se em uma 
Bücherwesenque, porém, satisfazia essencialmente as exigências dos colecionadores, dos bibliófilos e dos comerciantes de livros. Decorria disso a presença de um hiato de natureza científica entre a Bibliografia como ciência e a bibliofilia enquanto conhecimento prático específico.

A Bibliografia, em seu sentido mais amplo era, de fato, para Ebert, o codex diplomaticus da História Literária, relativo somente ao valor científico e histórico da produção literária de todas as nações e de todos os tempos. $\mathrm{Na}$ falta desses termos e dessas condições, a Bibliografia já não era mais ciência, mas expressava instâncias de outra natureza e se aplicava a interesses exclusivamente locais ou particulares.

O ensino da Bibliografia e da História Literária, que Ebert sentia como próximos e complementares eram, portanto, os dois requisitos da formação bibliotecária. Os bibliotecários, assim, deveriam se ocupar, profissional e disciplinarmente, da Bibliografia, enquanto na prática deveriam se tornar especialistas no uso dos repertórios, rigorosos no método das citações e cultores/conhecedores da literatura estrangeira. Portanto, o bibliotecário devia ser um erudito que, mediando entre exigências tanto práticas quanto logísticas, junto às necessidades de recuperação e de consulta dos livros tinha ainda que preservar a estrutura ordenadora do saber através de uma localgedächtnis, isso é, uma espécie de memória topográfica onde valeriam adjacências e afinidades temático-disciplinares. Tais características, pelo contrário, mais tarde seriam desvalorizadas por Schrettinger, que quebraria tal estrutura proposta por Ebert depois da introdução, no interior das classes, de um número consecutivo com a finalidade prioritária de controlar o crescimento das coleções.

Sobre os catálogos Ebert sugeria, de fato, estabelecer a atribuição disciplinar dos volumes, primeiro implantando o catálogo sistemático e, em seguida, derivando deste o alfabético nominal. Ele estava convencido que, dessa maneira, seria mais fácil controlar a distribuição topográfica efetiva dos livros. Todavia, essa solução técnica foi, por exemplo, fortemente criticada por Schrettinger em uma resenha de 1914 (SCHRETTINGER, 1914). 
Ebert tentara precocemente, já em 1811, tratando a matéria bibliotecária, e o fizera através de um opúsculo sobre bibliotecas públicas universitárias, isso é, Ueber öffentliche Bibliotheken (Fig. 4), no qual, lamentando o abandono das bibliotecas alemãs, fornecia indicações sobre a potencialização das coleções através da obrigação de impressão, a entrega das coleções por parte de quem teve encargos acadêmicos, e a venda dos duplos e das edições superadas; ainda, sobre uma melhor organização dos catálogos; e também sobre a formação dos bibliotecários, que não devia limitar-se somente a umas poucas disciplinas.

Figura 4 - Ueber öffentliche Bibliotheken (1811)

\section{ueber}

Dffentliche 2 Sibliotbelen

beforbers

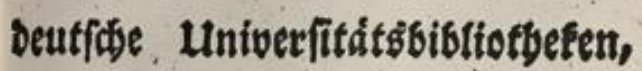

ant

\section{Borโ́ீlågé-}

Ju einet swed máßigen Einriøtung

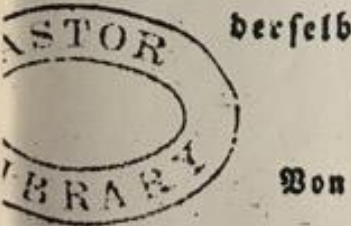

Stiebrid) 200ipg EGert.

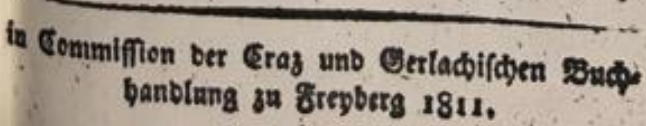

Fonte: Arquivo Alfredo Serrai. 
O grau de publicidade de uma biblioteca (isso é, sua abertura para o externo) dependia, para Ebert, de quem a financiava e de quem a frequentava e, no caso das bibliotecas alemãs, a situação complicada dependia, basicamente, do fato de as mesmas não serem apoiadas financeiramente nem pela nobreza feudal nem pela Igreja. A pequena obra de 1811 coloca-se, assim, como uma primeira tomada de posição a favor de um financiamento substancial das bibliotecas públicas; com exceção de Schrettinger, ninguém antes manifestara a mesma exigência. Deve-se destacar que Ebert, porém, não patrocinava somente um aumento dos orçamentos, mas recomendava também e principalmente uma ampliação dos usuários públicos, além de amplas facilitações para o empréstimo.

Tanto para Ebert como para Schrettinger a finalidade da atividade da biblioteca era o serviço público; mas, enquanto para Ebert a Bibliothekwissenschaft consistia na gestão e fruição da biblioteca, para Schrettinger, por outro lado, ela se expressava prioritariamente na busca dos livros, isso é, no uso dos catálogos.

Esta perspectiva diferente explica-se, principalmente, com a diversa situação histórica local das bibliotecas implicadas na experiência dos dois bibliotecários-bibliógrafos: em Dresden, a biblioteca era enquadrada na impostação que se inspirava a de Francke para a Biblioteca Bunaviana que Ebert pretendia imitar ${ }^{7}$; por outro lado, em Munique, a biblioteca encontrava-se dominada pelas avalanches de livros que chegaram em seguida à secularização das bibliotecas monásticas, havendo assim a exigência primária de individuar os livros úteis, razão pela qual a Schrettinger interessavam, em primeiro lugar, os catálogos enquanto instrumento de salvação do caos ${ }^{8}$ !

Evidentemente, os sistemas de ordenação anteriores, de tipo filosóficocientífico, entraram em crise, e a secularização, ordenada no final do século XVIII pelo imperador José II, filho de Maria Teresa e iluminista como a mãe,

\footnotetext{
7 Um importante texto explicativo sobre Ebert e seu relacionamento com a situação bibliotecária e biblioteconômica alemã está em Nestler (1960).

8 Sobre isso, cf. Jochum (1991, p. 8).
} 
levava a uma reviravolta dos esquemas organizadores, que Schrettinger considerava sem dúvida ultrapassados.

O tema da formação e da profissão bibliotecária, que Ebert já mencionara em Ueber öffentliche Bibliotheken, será em seguida desenvolvido em sua obra Die Bildung des Bibliothekars (Fig. 5), impressa em 1820.

Enquanto no passado o bibliotecário era um arquivista (figura que, hoje, na Itália, seria chamada de "bibliotecário conservador"), com o desenvolvimento das ciências, escreve Ebert, o bibliotecário tornava-se, de um lado, o próprio maieuta das coleções e, do outro, o mediador entre estas e o leitor. Portanto, o bibliotecário, para poder realizar de maneira plena o papel de mediador, devia ampliar seu preparo e construir para si uma personalidade criativa e competente no plano científico, para responder às exigências de preservação, mas, acima de tudo, de atualização. Não por acaso, a obra de Ebert, intitulada exatamente Die Bildung des Bibliothekars - que pode ser traduzida como 'a formação do bibliotecário' - deve ser entendida em particular com um verdadeiro 'método da biblioteconomia'. 
Figura 5 - Die Bildung des Bibliothekars (1820)

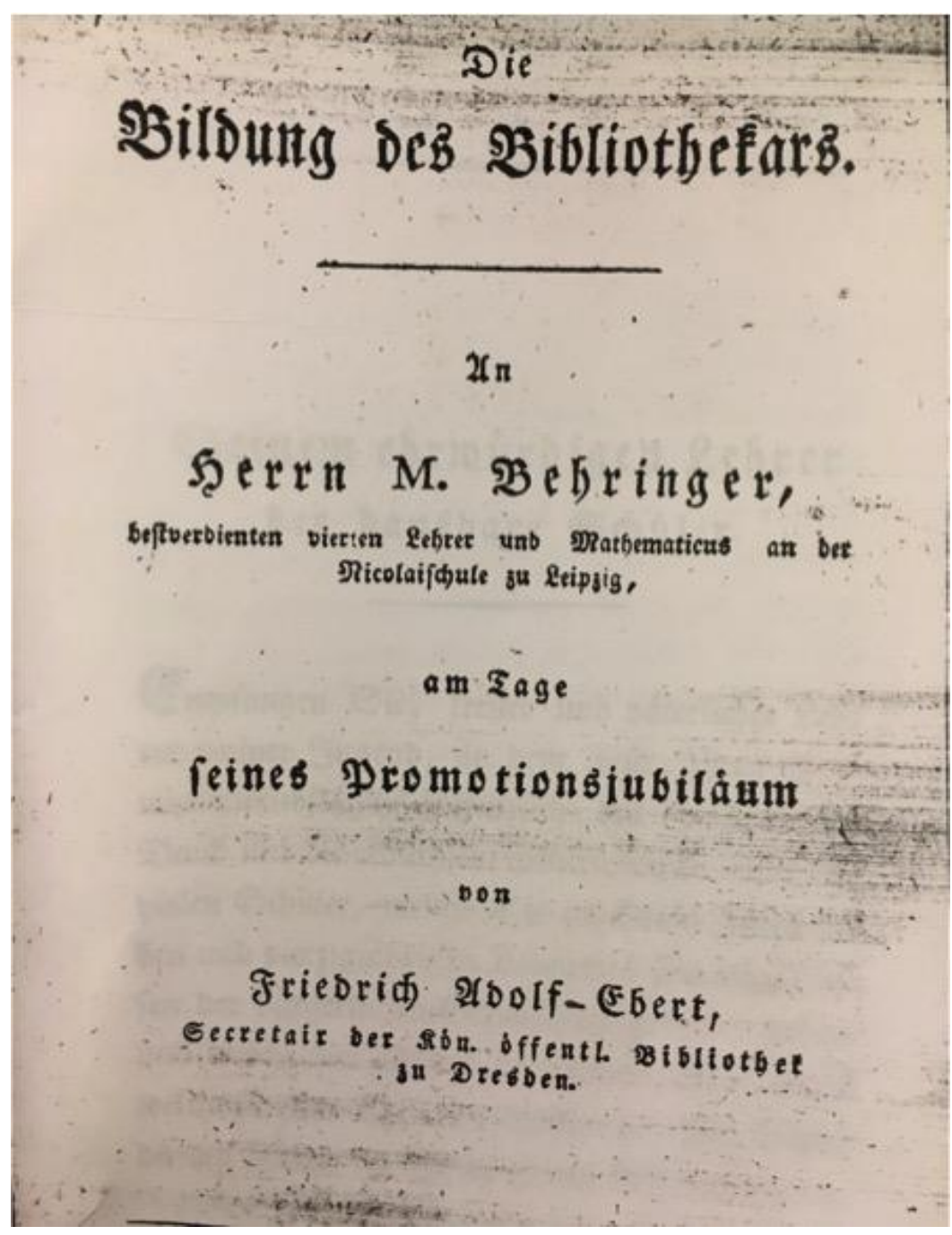

Fonte: Arquivo Alfredo Serrai.

Útil para enquadrar a concepção ebertiana pode ser a análise dos verbetes 'Bibliografia' e 'Biblioteconomia', que o próprio Ebert redigiu na grande Enciclopédia científica alemã da época, a Allgemeine Encyclopedie der Wissenschaft und Kunste; aqueles verbetes abrangem desde a Bibliographie até à Bibliothekwissenschaft. ${ }^{9}$

A 'Bibliografia', como já adiantamos, é por Ebert dividida em pura e aplicada: a pura ocupa-se em definir os livros e a escrita de todas as nações e de todas as épocas, bem como o conjunto das ciências de um ponto de vista

\footnotetext{
${ }^{9}$ Além de Bibliografia e Biblioteconomia, encontram-se os de: Bibliomania, Bibliofilia, Biblioteca e Bibliotecas. Cf. Ebert (1823a, 1823b).
}

Inf. Inf., Londrina, v. 23, n. 2, p. $203-231$, maio/ago. 2018 
que privilegia literatura e conteúdos; aquela aplicada, por outro lado, concerne os aspectos exteriores, descritivos ou históricos das publicações. Como instrumentos da Bibliografia eram apontados: o conhecimento das línguas, do enciclopedismo, da história e da literatura em geral; e como disciplinas auxiliares, a cronologia, a paleografia, a história da impressão e a história da arte, em particular para as xilografias e as calcografias ${ }^{10}$, a história das bibliotecas e a história do comércio de livros.

Por outro lado, com 'Biblioteconomia' Ebert entendia a gestão bibliotecária realizada com as necessárias operações e capacidades (ordenação, desenvolvimento das coleções, manutenção da instituição, colocação dos livros e sua catalogação). Três eram os catálogos necessários por ele prescritos: o topográfico (localkatalog), o alfabético por autores (alphabetische-nominal katalog), e o real (real-katalog). Esse último era estruturado de forma sistemática e dotado de um índice por assuntos que correspondia em parte ao das estantes, com a exceção do formato dos volumes.

Ebert, também, apontava a utilidade dos catálogos especiais: dos manuscritos, dos incunábulos (em ordem cronológica), dos impressos em pergaminho, das coleções especiais (oferece o exemplo das aldinas), e das relíquias. Porém, todos eles deviam - ponto crucial - ser depois incluídos no catálogo geral! Ebert ultrapassa, assim, com suas prescrições, a realidade atual dos muitos catálogos especiais online (os silos), raramente reunidos para facilitar quem os consulta!

\section{MARTIN WILIBALD SCHRETTINGER (1772-1851) ${ }^{11}$}

Schrettinger (Fig. 6) era um beneditino alemão, bibliotecário primeiro no Mosteiro de Weissenhohe, em seguida, com a chegada em Munique, trabalhando como bibliotecário na Königliche Hofbibliothek (hoje Bayerische

\footnotetext{
$10 \mathrm{~N}$. T: arte de gravar em metal.

11 Cf. Hilsenbeck (1914), Remy (1964), Serrai (1983), Jochum (1991), Schrettinger (2003) e Knedlik (2011).
} 
Staatsbibliothek, na qual, entre outras coisas, encontram-se guardados seus diários de 1793 a 1850 e sua autobiografia manuscrtta).

Figura 6 - Martin Wilibald Schrettinger (1772-1851)

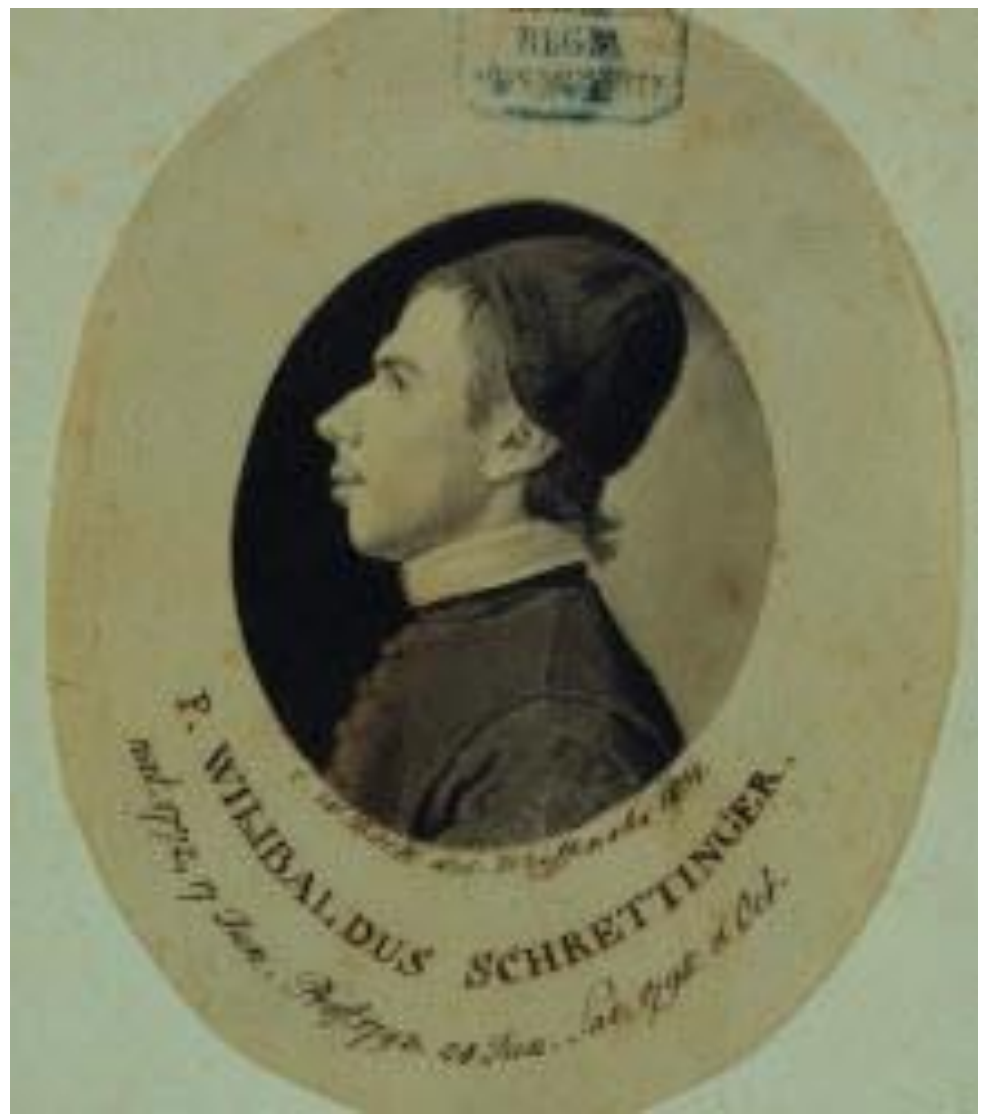

Fonte: <https://www.flickr.com/photos/krzysztof_m/8409316238>

Suas principais obras são:

- Versuch eines vollständigen Lehrbuches der Bibliothek-Wissenschaft oder Anleitung zur vollkommenen Geschäftsführung eines Bibliothekärs (Vol. 1 (Seções 1-2, 1808, e Seção 3, 1810); Vol. 2 (Seção 4, 1829 (Fig. 7), mais índice completo). Trata-se, conforme as intenções do autor, de um primeiro manual de Biblioteconomia com o cauteloso subtítulo de "introdução a uma gestão perfeita para os bibliotecários".

- Handbuch der Bibliothek-Wissenschaft, Viena, 1834, reimpresso por Weidmann, Hildesheim 2003 (era um manual de Biblioteconomia). 
Figura 7 - Versuch eines vollständigen Lehrbuches der Bibliothek-Wissenschaft oder Anleitung zur vollkommenen Geschäftsführung eines Bibliothekärs (1829)

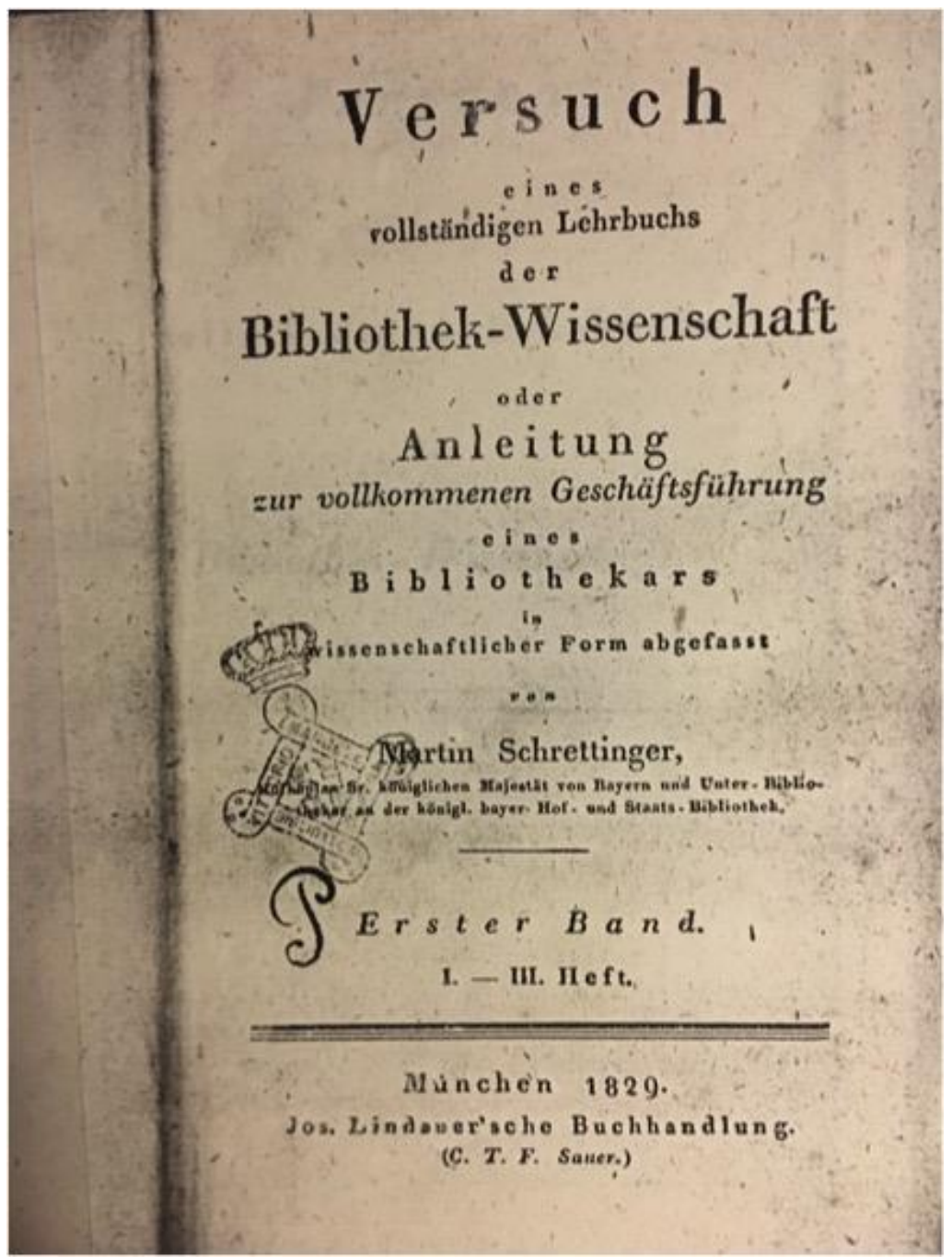

Fonte: Arquivo Alfredo Serrai.

Schrettinger é considerado o fundador da Biblioteconomia moderna. Seu Versuch eines vollständigen Lehrbuches der Bibliothek-Wissenschaft marca, de fato, o nascimento oficial da Biblioteconomia como Bibliothek-Wissenschaft,isso é, como disciplina autônoma dotada de rigor conceitual.

Porém, Schrettinger não se limita a expor os conhecimentos necessários aos bibliotecários, mas se concentra também no conjunto das competências bibliotecárias e, com ele, a História Literária - que fora, se não central, uma referência importante no pensamento de Ebert - permanece no fundo, 
enquanto adquirem destaque as lógicas indexadoras singulares e sua relação pragmática.

A expressão mais madura do pensamento de Schrettinger encontra-se no último dos 4 fascículos que compunham aquela sua primeira teorização (o Versuch); com efeito, nesse IV fascículo, ele chega a renegar em parte algumas afirmações feitas nos três anteriores (os fascículos foram impressos ao longo de 21 aos!), como consequência natural de um pensamento que ia se formando e que se completava através da experimentação efetiva e concreta das lógicas pensadas e, em seguida, implementadas.

De fato, Schrettinger é lembrado em particular por iniciar, em 1819, um Realkatalog da Hofbibliothek de Munique, isso é, um catálogo semântico real (de res-rebus, em latim coisas, objetos); tratava-se de um catálogo alfabético de todas as entradas por assunto da biblioteca, às quais remetiam as vozes contidas em um catálogo por autores e em outro para as colocações atribuídas aos livros nas estantes.

Em suas palavras, com um catálogo real buscava-se "[...] tornar o mais rápido possível a recuperação dos livros úteis para satisfazer exigências literárias de todos os gêneros" ${ }^{12}$ (SCHRETTINGER, 1829, p. 17), mas o dilema permanecia sobre a ordenação interna: catálogo alfabético ou sistemático por assuntos?

Interessante constatar que ainda não foi totalmente resolvida essa dúvida, talvez uma das mais complexas questões de nossas disciplinas documentárias, enquanto já na época Schrettinger, no III fascículo do Versuch, encontrara uma solução com a proposta de um índice alfabético dos assuntos que remetia a uma estrutura bibliográfico-disciplinar.

Schrettinger considerava oportuno, para satisfazer as duas exigências da recuperação de um autor ou de uma obra conhecidos, construir um catálogo real (dos assuntos tratados nos livros), que podia ser consultado alfabeticamente, enquanto para encontrar os documentos com base nos

12 "Die Einrichtung einer Bibliothek muss so beschaffen sein, dass sie das schnelle Auffinden der zur Befriedigung eines jeden literarischen Bedürfnisses nötigen Bücher möglichst befördere". 
assuntos era, por outro lado, necessário um catálogo científico (ou seja, um sistema catalográfico formado pela sequência dos catálogos especiais sistemáticos), onde as obras eram evidenciadas com base no conteúdo, na tipologia formal, nas relações por temas ou áreas com outras obras, e no período e área geográfica de aparecimento.

Fala-se em aparecimento e não em edição, e em obras e não em edições, tanto porque Schrettinger sugere acumular impressos e manuscritos em um catálogo real único, tanto porque o catálogo real, diferentemente daquele científico-sistemático, pode evidenciar também somente as obras e não necessita se ocupar das diferentes manifestações editoriais para as quais se remete, por outro lado, eventualmente, ao catálogo alfabético dos nomes. Conforme uma metáfora eficaz de Serrai, o catálogo real era, praticamente, um dicionário literário, o catálogo sistemático de tipo científico, por outro lado, um atlas para se deslocar naquela mesma literatura (SERRAI, 1983, p. 49).

Schrettinger, todavia, como antecipamos, no IV fascículo chega a renegar quanto afirmado sobre catálogos sistemáticos, experimentando como aquela estrutura, enquanto podia ser um ótimo exercício filosófico, na prática da busca produzia mais confusão que resultados na finalidade da recuperação dos livros de interesse.

Schrettinger conclui, portanto, no IV fascículo, com uma clara recusa dos catálogos sistemáticos, em favor daqueles sempre semânticos, porém 'reais', mais ágeis e fáceis por meio de uma estrutura alfabética, linear e não interpretativa como aquela sistemática. Tratava-se da vitória dos dados literários puros, como autor, título, disciplina, objetos, datas e línguas, sobre informações relativas a uma classificação dos assuntos; ganhava assim a simplificação da realidade através de uma lista alfabética sobre a complexidade de sua representação filosófico-disciplinar realizada através de uma estrutura semântica dendrítica, ou seja, ramificada.

Na substância, conforme o pensamento biblioteconômico elaborado por Schrettinger, precisava implementar, como base, um catálogo alfabético e, eventualmente, em seguida, criar a partir dele tantos catálogos especiais para tantos âmbitos específicos individualizados na biblioteca, assim que os 
catálogos sistemáticos de uma coleção não eram mais relativos em geral ao universo do que podia ser conhecido, mas à efetiva utilidade e ao uso mais provável daqueles livros individuais nos contextos particulares daquela biblioteca.

Schrettinger, em seguida, estabelece detalhadamente todos os procedimentos para construir essa organização catalográfica, desde a escolha dos cabeçalhos até o controle dos sinônimos e, ainda, das remissivas, das quais não podemos aqui falar; o que merece ser apontado é a impostação dos níveis de qualidade dos catálogos que ele estabelece. Schrettinger define vários tipos de catálogos: o puro nominal, o que fornece também os espólios de miscelâneas e periódicos e os nomes das responsabilidades secundárias (curadores, epitomadores ${ }^{13}$, colaboradores...), o catálogo que dava também notícias de aprofundamento sobre autores ou sobre circunstâncias literárias e editoriais dos textos bem como as críticas relativas e as resenhas, até os multíplices catálogos especiais que ofereciam dentro da estrutura sistemática a evidência das partes individuais de um livro de forma separada (prefácios, sumários, capítulos vários).

Schrettinger, através dessa estrutura catalográfica detalhada, parece antecipar assim aquilo que será o terreno comum de Biblioteconomia, Ciência da Informação e Documentação, lembrando-nos, em parte, a conexão entre a estrutura da Bibliotheca Universalis (1545) e a das Pandectae (1548-1549) gesnerianas, e antecipando as Rules for a Printed Dictionary Catalog de Cutter (1876), principalmente pela proposta de expressar os conceitos dentro de uma ordem alfabética.

Por outro lado, a premissa na qual Schrettinger se fundamentara no I fascículo do Versuch, e que permanecerá o tema de partida também de seu Handbuch (que veremos em breve), definindo a 'biblioteca' como um conjunto conspícuo de livros cuja organização devia permitir ao usuário de individualizar e, em, seguida, recuperar um livro no menor tempo possível, não deixava saídas: na eficiência dos procedimentos residia a utilidade de uma biblioteca.

\footnotetext{
${ }^{13}$ N.T. : Aqueles que escrevem epítomes (compêndios; resumos dos conhecimentos relativos a uma área).
}

Inf. Inf., Londrina, v. 23, n. 2, p. $203-231$, maio/ago. 2018 
Uma visão que, com evidência, revertia aquela tradicional, que via na biblioteca, em primeiro lugar, um depósito cultural, um monumento documentário, de valor indiscutível (prescindindo do uso e da fruição). Derrubando a importância da erudição e atacando os sistemas classificados tradicionais, Schrettinger colocava o eixo do nascimento da moderna Biblioteconomia na união de conhecimentos comuns e empirismo (projeto de regras e experimentação de sua aplicação).

Ebert (1821) criticara fortemente o conteúdo dos primeiros três fascículos de Schrettinger através de uma resenha anônima publicada na Jenaische Allgemeine Literatur-Zeitung (Fig. 8). Na verdade, lendo bem nas entrelinhas, se deduz que o contraste entre os dois era realmente mais 0 resultado de uma competição em primeiro lugar no plano pessoal; os apontamentos que Ebert faz para Schrettinger são em sua maioria pouco justificadas, trata-se quase sempre de sutilezas não substanciais. Tanto por citar um exemplo: lá onde Schrettinger, no primeiro fascículo do Versuch, declarara que uma biblioteca é uma conspícua coleção de livros cuja ordenação deve colocar qualquer leitor na condição de poder dela fruir sem perder muito tempo, Ebert se opõe a esse diagnóstico articulado afirmando que a definição de biblioteca é simples e somente aquela de uma conspícua coleção de livros. 
Figura 8 - Jenaische Allgemeine Literatur-Zeitung (1821)

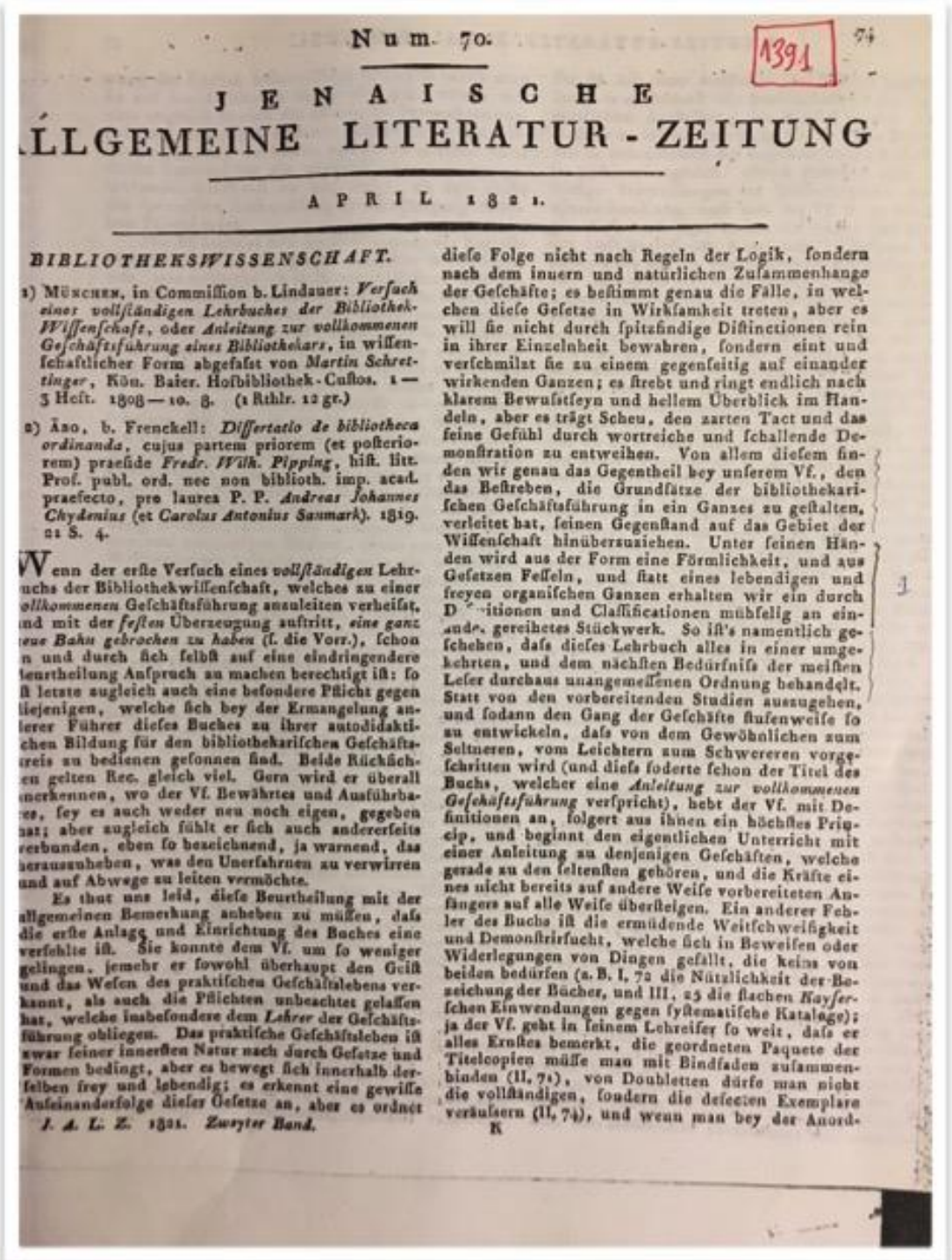

Fonte: Arquivo Alfredo Serrai.

Schrettinger epitomará ${ }^{14}$, finalmente, em 1834, aquilo que tinha meticulosamente ilustrado nos 4 fascículos do Versuch, publicando em Viena, em favor dos iniciantes, o Handbuch der Bibliothek-Wissenschaft (Fig. 9), apresentado como um guia certeiro para organizar assim bibliotecas públicas bem como coleções particulares.

${ }^{14} \mathrm{~N}$. T: Ou seja, redigirá um epítome.

Inf. Inf., Londrina, v. 23, n. 2, p. 203 - 231, maio/ago. 2018

http://www.uel.br/revistas/informacao/ 
Figura 9 - Handbuch der Bibliothek-Wissenschaft (1834)

\section{5) a ก \\ \&\& 5 \\ ล̧ibliotbet=-2̧inemichaft,}

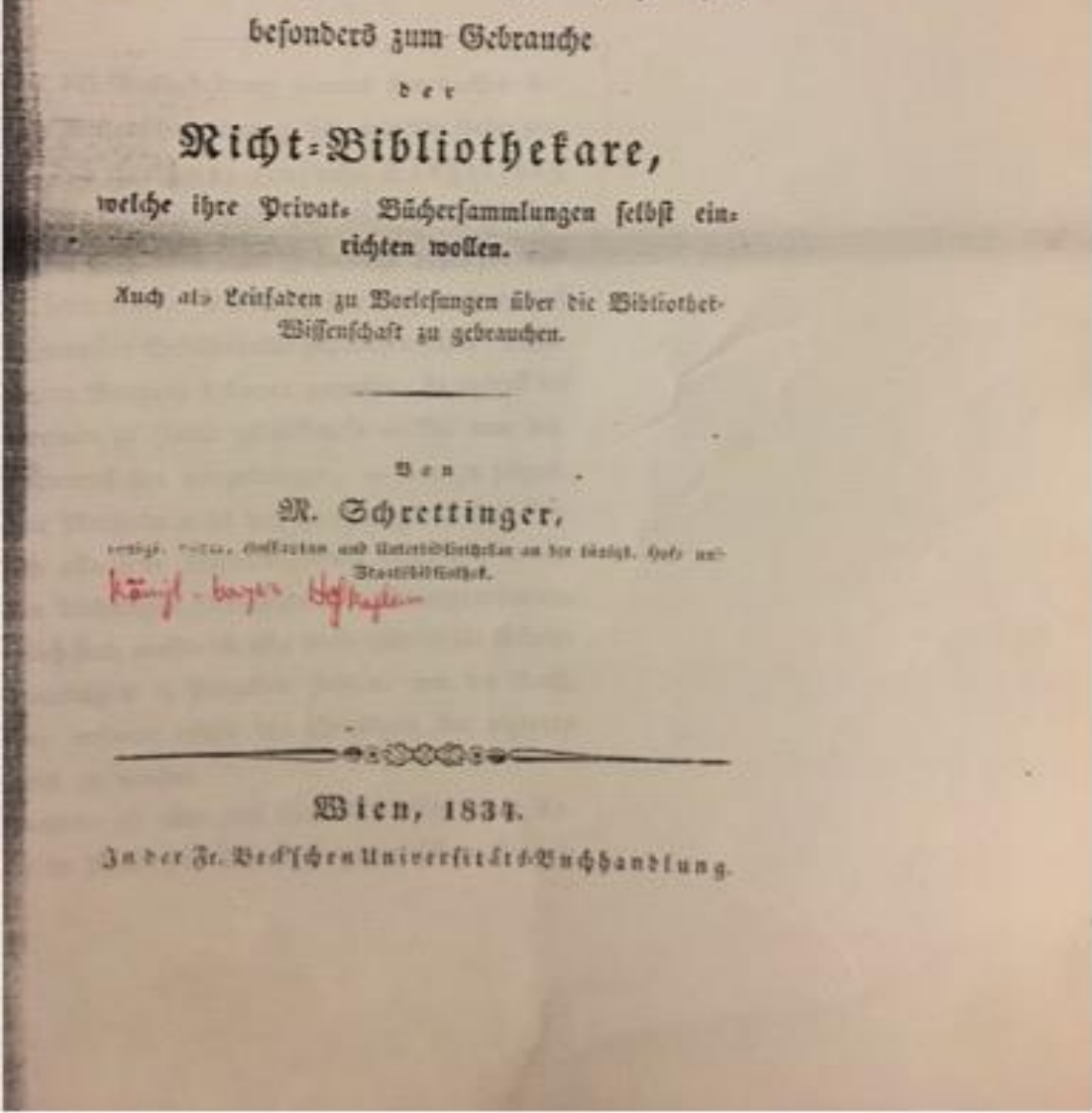

Fonte: Arquivo Alfredo Serrai.

Partindo de uma definição de biblioteca, dos fundamentos da Biblioteconomia e de suas relações para satisfazer determinadas necessidade literárias, Schrettinger entrava, em primeiro lugar, no detalhamento da ordenação física de uma biblioteca (separando entre si e do resto tanto os manuscritos como os incunábulos). Na segunda parte era depois descrita a preparação do catálogo alfabético, partindo da cópia dos títulos através da escolha da palavra considerada significativa, ou seja, da palavra de ordem, que podia ser, em primeiro lugar, o sobrenome do autor. A terceira parte preocupava-se, ainda, com os catálogos especiais, isso é: aqueles compostos 
sobre âmbitos singulares ou assuntos específicos, a não serem confundidos com o catálogo geral sistemático por disciplinas.

La segunda seção dessa terceira parte concentrava-se, por outro lado, nos catálogos reais, dos quais Schrettinger enuncia o conceito e as finalidades; enfim, a terceira seção descrevia o Potenzirung (ou "potencialização") desses catálogos, ou seja, seu porte informacional em termos de detalhes de referências. Essa última parte remete também aos níveis de catálogos reais dos quais ele expunha de forma aprofundada também no Versuch. De qualquer maneira, deve ser considerado o princípio utilitarista, segundo o qual a biblioteca, conforme Schrettinger, sempre devia responder à finalidade central de elevar o nível da utilidade e do progresso geral.

No final do Handbuch, Schrettinger aponta uma série de características que o bibliotecário devia possuir: uma educação geral de tipo literário, um conhecimento biblioteconômico tanto teórico quanto prático aprofundado, sem ser nem um especialista, nem um escritor, além de desfrutar de uma boa reputação humana, intelectual e moral. Para Schrettinger, portanto, o bibliotecário era em primeiro lugar um gestor, dedicado à finalidade do melhor funcionamento da biblioteca, mas não the era reconhecida uma incidência performativa sobre as coleções; ainda afirma que ao bibliotecário devem ser fornecidos os meios necessários para uma vida digna, assim que possa exercer seu papel de maneira tranquila e adequada, e receber confiança em sua gestão e em sua honestidade.

No Handbuch Schrettinger cita com frequência 0 manual de Biblioteconomia que, no entanto, um ano antes, o dinamarquês Christian Molbech publicara com o título de Ueber Bibliothekswissenschaft oder Einrichtung und Verwaltung öffentlicher Bibliotheken (Leipzig, 1833) (Fig. 10), e que se apresenta como um desenvolvimento e uma síntese tanto das indicações de Ebert sobre as funções e as características do bibliotecário profissional como as de Schrettinger sobre a organização dos catálogos bibliotecários, mas englobando também questões como, por exemplo, aquelas arquitetônicas relativas aos espaços, profissionais para a atualização dos funcionários, além de outras de natureza administrativa e de gestão. 
Figura 10 - Über Bibliothekswissenschaft oder Einrichtung und Verwaltung öffentlicher Bibliotheken (1833)

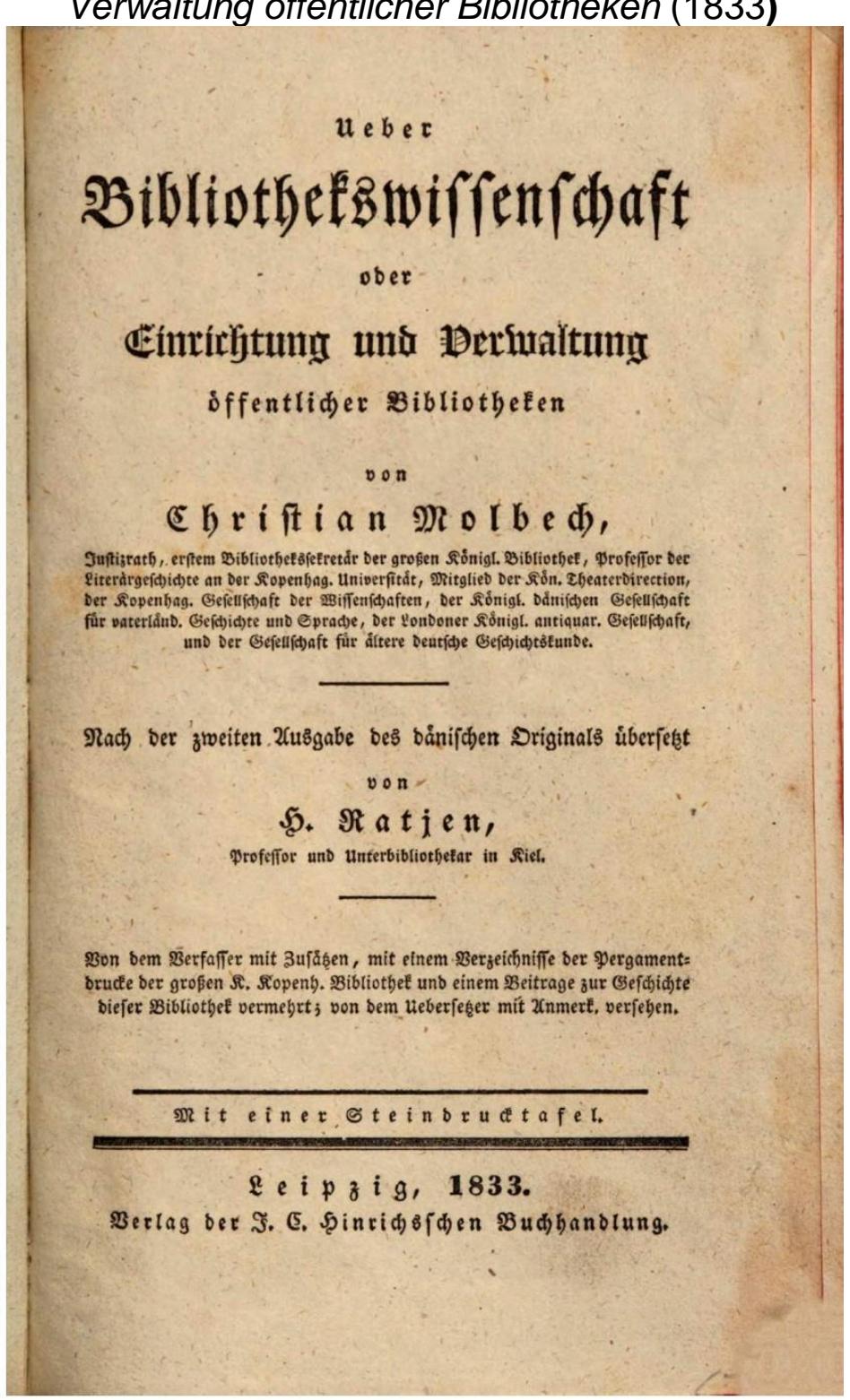

Fonte: <http://reader.digitale-

sammlungen.de/de/fs1/object/display/bsb11093572_00005.html>

O dinamarquês Christian Molbech (1783-1857) era bibliotecário da Biblioteca régia em Kopenhagen e ainda professor de Historia litteraria na Universidade da mesma cidade. ${ }^{15}$ Depois de Schrettinger houve numerosos repertórios bibliotecários (Schmidt, Budik, Richter, Zoller...) e era evidente, portanto, que uma nova disciplina iniciara. Molbech insere-se nessa trilha, porém se destacando através de seu tratado Ueber Bibliothekswissenschaft

${ }^{15}$ Veja-se sobre Molbech: Serrai (1990a, p. 752-783), Steenstrup (1887-1905).

Inf. Inf., Londrina, v. 23, n. 2, p. 203 - 231, maio/ago. 2018 http://www.uel.br/revistas/informacao/ 
oder Einrichtung und Verwaltung öffentlicher Bibliotheken, publicado pela primeira vez em $1829,{ }^{16}$ e reimpresso em alemão em 1833 editado por Henning Ratjen, professor de Bibliografia e vice-diretor da biblioteca universitáriade Kiel. O título da obra pode ser traduzido como "Sobre a Ciência das bibliotecas ou instituição e administração das bibliotecas públicas", identificando com "ciência das bibliotecas' a Biblioteconomia. O trabalho de Molbech é, de fato, a primeira descrição orgânica da Biblioteconomia como disciplina (teoria, práxis, e sua aplicação), que resume as funções científicas e as características do bibliotecário conforme Ebert, e a organização bibliotecária assim como estabelecida por Schrettinger.

A 'Biblioteca' representa, conforme essa configuração mais ampla, tanto um depósito cultural (visão histórico-literária), como um arquivo para a formação e a atualização (visão cultural, porém biblioteconômica). Molbech afirma, com efeito, que as instituições bibliotecárias, a partir do final do século XVIII, tornaram-se determinantes para a preservação e a transmissão do patrimônio científico e cultural. De grande novidade e também atualidade é a constatação do bibliotecário dinamarquês que o conhecimento se cria e preserva através de dois pilares institucionais: as comunidades científicas, constituídas por escolas, academias, sociedades e universidades, que são dedicadas à produção e à criação de conhecimento, e as instituições bibliotecárias, cujos serviços e funções garantiam daquele conhecimento a manutenção, a preservação, a disseminação e a disponibilização.

\section{CONSIDERAÇÕES FINAIS}

Os elementos que aproximam as teorias de Ebert e Schrettinger, e que são fundamentais para a Biblioteconomia, como será de fato demonstrado também por Molbech, são essencialmente dois: a figura do bibliotecário e o catálogo. O bibliotecário deve ser bem selecionado, além de ser apoiado tanto financeiramente como nas ações de atualização e de estudo: para Ebert,

16 Título original: Om offentlige Bibliotheker, Bibliothekarer, og det, man har kaldet Bibliotheksvidenskab., Kiöbenhavn, Gyldendal, 1829. v. 2. 
erudito, estudado e culto homem de letras e de ciência; para Schrettinger, por outro lado, em primeiro lugar uma pessoa dotada de qualidades que contribuem a torná-lo principalmente um gestor racional e agudo do sistema bibliotecário.

Portanto, Ebert, mesmo baseando no pragmatismo sua teoria, preserva, todavia, a configuração tradicional literária, enquanto Schrettinger volta-se marcadamente para o funcionamento e a eficiência dos instrumentos técnicos e do sistema. O catálogo, com efeito, é porém o elemento que junta os dois bibliotecários, enquanto é visto por ambos, prescindindo das escolhas de estrutura, como core business da biblioteca; sem o catálogo da coleção de livros constituída pelas coleções individuais não pode ser substanciado qualquer raciocínio nem bibliográfico nem biblioteconômico, seja a visão baseada naquela tradicionalmente erudita e literária, seja que se trate da nova e moderna impostação de tipo organizacional e gerencial.

Ebert e Schrettinger são, portanto, ambos protagonistas do renascimento no contexto alemão dos problemas ligados ao valor e ao uso da biblioteca, mesmo se seu contraste, tanto pela orientação metodológica como pelas questões de detalhes, acabou tradicionalmente por marcar uma separação no âmbito do panorama bibliográfico entre as questões práticas, técnicas e organizacionais, e aquelas tradicionais de natureza principalmente erudita e literária.

\section{REFERÊNCIAS}

BÜRGER, Richard. Friedrich Adolf Ebert: ein biographischer Versuch. Leipzig: R. Haupt, 1910.

EBERT, Friedrich Adolf. Bibliographie. In: ALLGEMEINE Encyclopedie der Wissenschaft und Kunste. Leipzig: Johann Friedrich Gleditsch, 1823a. Seit. 1, Teil 10, p. 47-73. 
. Bibliothekswissenschaft. In: ALLGEMEINE Encyclopedie der Wissenschaft und Kunste. Leipzig: Johann Friedrich Gleditsch, 1823b. Seit. 1, Teil 10, p. 47-73.

. Jenaische Allgemeine Literatur-Zeitung, n. 70-71, abr. 1821.

HEINEMANN, Otto von. Die Herzogliche Bibliothek zu Wolfenbüttel, 15501893: ein Beitrag zur Geschichte deutscher Büchersammlungen mit einem Anhang von Dokumenten und Archivstücken, Zweite, völlign eugearbeitete Auflage. Wolfenbüttel: J. Zwissler, 1894. p. 211-218.

HILSENBECK, Adolf. Martin Schrettingerund die Aufstellung in der Kgl. Hof-und Staatsbibliothek München. Zentralblatt für Bibliothekswesen, n. 31, 1914. p. 407-433.

JOCHUM, Uwe. Bibliotheken und Bibliothekare 1800-1900. Würzburg: Königshausenund Neumann, 1991.

KNEDLIK, Manfred. Schrettinger, Martin. In: Biographisch-Bibliographisches Kirchenlexikon (BBKL). Band 32 (Ergänzungen XIX), Bautz, Nordhausen, 2011, p. 1234-1239.

NESTLER, Friedrich. Friedrich Adolf Ebert und seine Stellung in national en Erbe der Bibliothekswissenschaft. Leipzig: Bibliographisches Institut, 1960.

REMY, Fernand. Unprécurseur de la bibliothéconomie moderne: Martin Schrettinger (1772-11851), Archives et Bibliothèques de Belgique, n. 35, p. 3-30, 1964.

RUIZ GARCIA, Elisa. Tipologia do livro. Tradução de Diná Marques Pereira Araújo. Cadernos de História, Belo Horizonte, v. 15, n. 23, p. 208-228, out. 2014. ISSN 2237-8871. Disponível em: $<$ http://periodicos.pucminas.br/index.php/cadernoshistoria/article/viewFile/P.223 7-8871.2014v15n23p208/7221 >. Acesso em: 15 jun. 2018.

SCHRETTINGER, Martin. Handbuch der Bibliothek-Wissenschaft. Neudruck der Ausgabe Wien, 1834, mit einem Nachwort und einer Bibliographie, hrsg. Von Holger Nitzschner, Stefan Seegerund Sandro Uhlmann. Hildesheim: Weidmann, 2003. . Jenaische Allgemeine Literatur-Zeitung, n. 91, 1914.

Versuch eines vollständigen Lehrbuchs der BibliothekWissenschaft oder Anleitung zurvollkommene Geschäftsführung eines Bibliothekars: in wissenschaftlicher Form abgefaßt. Müchen: Lindauer, 1829. 
SERRAI, Alfredo. La catalogazione semantica e leteoriedi Martin Schrettinger. In: Biblioteche e cataloghi. Firenze: Sansoni, 1983. p. 45-70.

. Christian Molbech. In: Storia della Bibliografia $X$, Specializzazione e Pragmatismo: i nuovi cardini della attività bibliografica. parte II. Roma: Bulzoni, 1990a. p. 752-783.

Friedrich Adolf Ebert. In: Storia della Bibliografia $\mathbf{X}$, Specializzazione e Pragmatismo: i nuovi cardini della attività bibliografica, parte II. Roma: Bulzoni, 1999b. p. 555-700. 1990b

Martin Schrettinger. In: Storia della Bibliografia $X$, Specializzazione e Pragmatismo: i nuovi cardini della attività bibliografica, parte II.Roma: Bulzoni, 1999c. p. 701-751. 1990c

STEENSTRUP, Johannes Christoffer Hagemann Reinhardt. Christian Molbech. In: DANSK biografisk Lexikon, XI. Bind. Maar - Müllner (1887-1905), p. 345-

354.

\title{
EBERT VERSUS SCHRETTINGER, FROM CULTURAL LOGIC (BIBLIOGRAPHY) TO LIBRARIAN LOGIC (LIBRARIANSHIP)?
}

\begin{abstract}
Introduction: After the fundamental bibliographic praxis of Gesner and after the cultural foundation discussed by Naudé, which unified practical demands and cultural foundations, the specific evidence sand the theoretical maturation of Bibliography and Librarianship are defined and interpreted in a perspective and a passionates cientific dialectic, by Friedrich Adolf Ebert and Martin Wilibald Schrettinger. Objective: To identify and analyze the specific contributions of Ebert and Schrettinger to the consolidation oft hepure Bibliographyand the birthof modern Librarianship. Methodology: It is a bibliographical background research, based on the interpretation of the sources of Ebert and Schrettinger in combination with literature review, through a historical approach. Results: Ebert and Schrettinger, having criticized each other's works, have always been illustrated in contraposition, but their clash, in reality, was the ground on which the bibliographical and librarian thinking of them began to be defined. Conclusions: The elements that approximate the the oriesof Ebert and Schrettinger, and which are fundamental for Librarianship, are essentially two: the figure of the librarian and the catalog. The librarian should be well-selected, in addition to being supported both financially and in the updating and study activities. The catalog, however, is the element that unites the two librarians (Ebert e Schrettinger): without the catalog of the collection of books made up of the individual collections, no reasoningcanbesubstantiated, neitherbibliographicalnorlibrarian, northeviewbasedon that traditionallye rudite and literary, if it is the new and modern configuration of organizational and managerial type.
\end{abstract}

Descriptors: Bibliography - Germany - 19th century. Librarianship - Germany - 19th

Inf. Inf., Londrina, v. 23, n. 2, p. $203-231$, maio/ago. 2018

http://www.uel.br/revistas/informacao/ 


\title{
EBERT VERSUS SCHRETTINGER, DE LA LÓGICA CULTURAL (BIBLIOGRAFÍA) A LA LÓGICA BIBLIOTECARIA (BIBLIOTECOLOGÍA)?
}

\begin{abstract}
RESUMEN
Introducción: Después de la fundamental praxis bibliográfica de Gesner y trasel fundamento cultural discutido por Naudé, que unifico exigências prácticas y cimientos culturales, las evidencias específicas y La maduración teórica de La Bibliografía y Biblioteconomía pasan a ser definidas y teorizadas desde una perspectiva de contraposición y una dialéctica científica apasionada, por Friedrich Adolf Ebert y por Martin Wilibald Schrettinger. Objetivo: Identificar y analizar lãs contribuciones específicas de Ebert y Schrettinger ante lac onsolidación de La Bibliografía pura y Del nacimiento de la Biblioteconomía moderna. Metodología: Se trata de una investigación de fondo bibliográfico, realizada a partir de la interpretación de lãs fuentes de Ebert y Schrettinger em combinación com revisión de literatura, por medio de un enfoque histórico. Los resultados: Ebert y Schrettinger, habiendo criticado cada uno los trabajos del otro, desde siempre han sido ilustrados encontraposición, pero su embate, enrealidad, fue el terreno sobre el cual pasó a definir se el pensamiento bibliográfico y biblioteconómico de ambos. Conclusiones: Los elementos que aproximan lãs teorías de Ebert y Schrettinger, y que son fundamentales para la Biblioteconomía, son esencialmente dos: la figura Del bibliotecario y el catálogo. El bibliotecario debe estar bien seleccionado, además de ser apoyado tanto financieramente como em la sacciones de actualización y de estudio. El catálogo, em efecto, es el elemento que une a los dos bibliotecários (Ebert e Schrettinger): sin el catálogo de la colección de libros constituida por las colecciones individuales no puede ser sustância do ningún raciocinioni bibliográfico ni biblioteconómico, sea la visión basada en aquella tradicionalmente erudita y literaria, sea que se trata de la nueva y moderna imposición de tipo organizacional y gerencial.
\end{abstract}

Descriptores:Bibliografía - Alemania - Siglo XIX. Biblioteconomía - Alemania - Siglo XIX. Bibliografía y Biblioteconomía - Fundamentos. Friedrich Adolf Ebert (1791-1834). Martin WilibaldSchrettinger (1772-1851).

Recebido: 10.05 .2018

Aceito: 25.08 .2018 